تمائم تل تبلله وعلاقتها بعبادة أوزيريس

تمائم تل تبلله وعلاقتها بعبادة أوزيريس توعليس بعيا

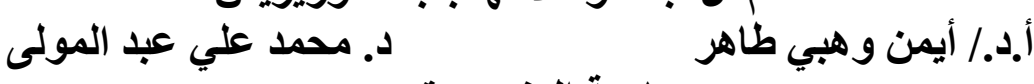

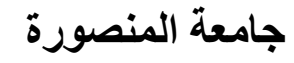

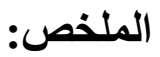

كثفت بعثة جامعة المنصورة المشتركة مع وزارة الآثار في الموسم الأول

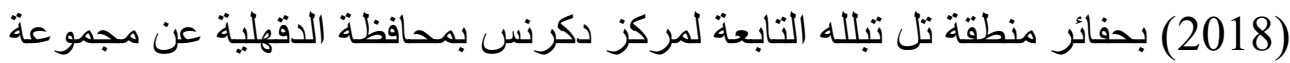

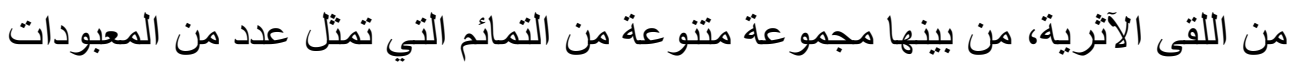

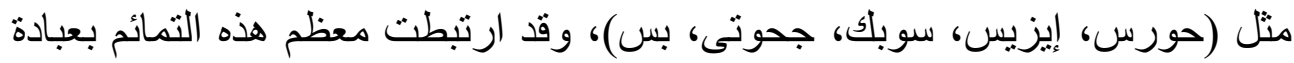

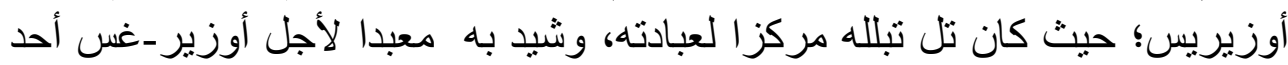

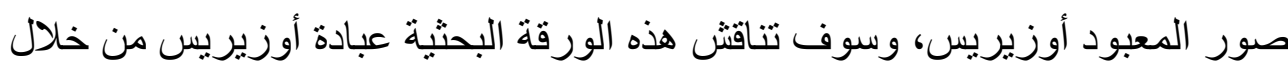

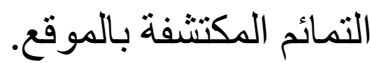

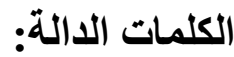

تبلله - تمائم- أوزيريس-إيزيس -سوبك- حورس- جحوتى- بس- تاورت- عبادةمعبد- را نفر - مصطبة أنية

\title{
Abstract
}

The Joint mission of Mansoura University and MoA revealed in their excavations at Tell-Tebilla near Dekerns at Daqahlia Governorate some archaeological findings among them there multiple collection of Amulets which represent a number of divinities like Horus, Isis, Sobek, Djhuty, Bes. These amulets connected with the worship of Osiris where Tell-Tebilla was his cult center and a temple erected for his there. The present paper deals with the worship of Osiris through the discovered amulets at the site.

Key words

Tebilla-Amulets-Osiris-Isis-Sobek-Horus-Djhuty-Bes-TaweretWorship-Temple-Ra nefer- Mastaba. 


$$
\text { أولا: موقع تلّ تبلاه و أهميته: محمد علي عبد المولى }
$$

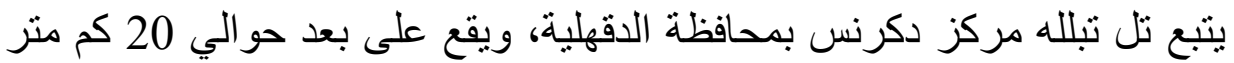

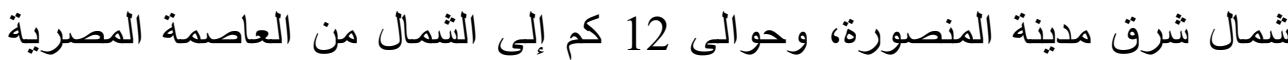

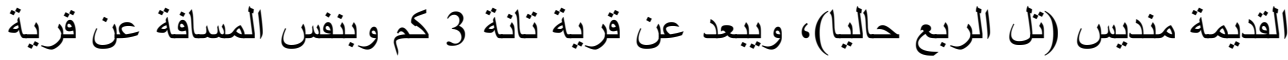
ميت فارس.

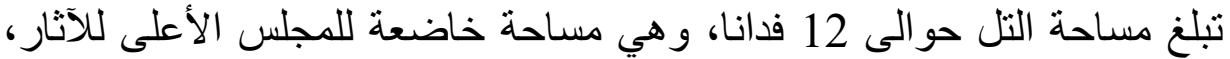

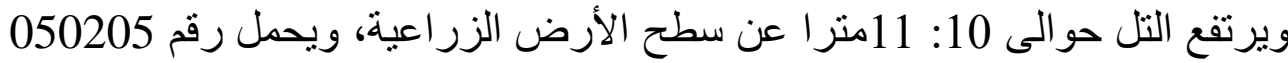

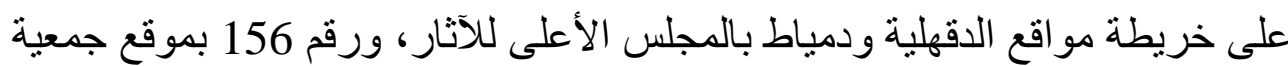

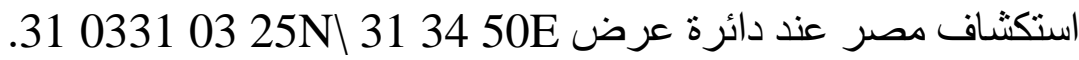
وقد عرف التل في المصادر العربية بعدة أسماء؛ مثل "تل تبله، تل تبلله، تل بله وتل

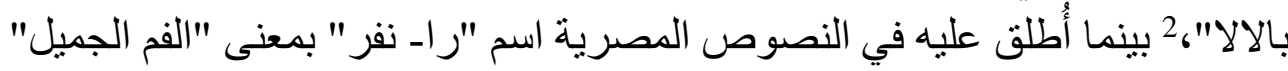

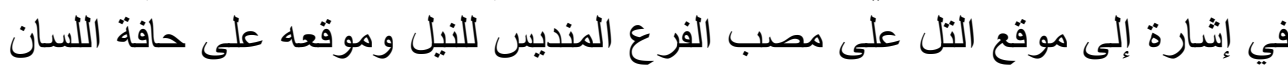
الممتد من بحيرة المنزلة التى تقع إلى الثمال، كما يثير مخصص الثيل المياة والمجرى 3.

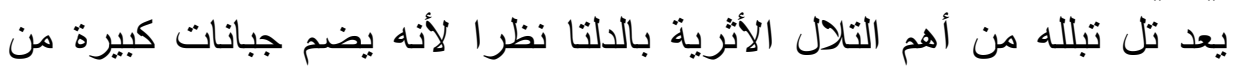

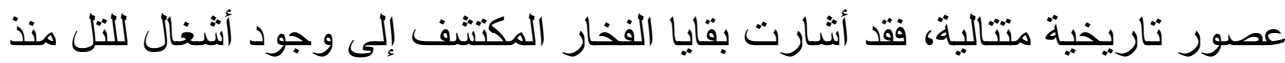

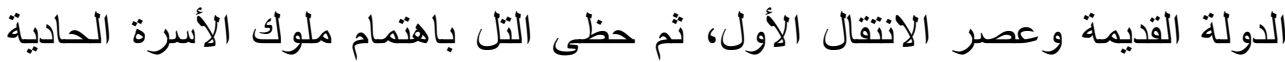

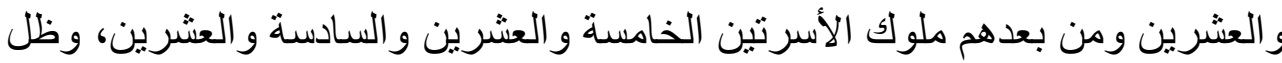

'J. Malek, "Tell Tebilla", LÄ VI (Wiesbaden: 1986), 354.

2 B. Porter and L. B. Moss, Topographical Bibliography of Ancient Egyptian Hieroglyphic Texts, Reliefs and Paintings, IV (Oxford 1952), 39; Malek, "Tell Tebilla", LÄ VI (1986), 354; L. Pavlish, G. Mumford, \& C. D'Andrea, Geotechnical Survey at Tell Tabilla, Northeastern Nile Delta, Egypt", in Z. Hawass \& L. Pinch-Brock (eds.), Egyptology at the Dawn of the Twenty-First Century, vol. 1 (2003), 361; L. Pavlish, G. Mumford, and A.C. D'Andrea), "Magnetic Survey at Tell Tebilla, Egypt," Field Archaeology session, The 32nd International Symposium, Archaeometry, (Mexico City 2000), 269.

${ }^{3}$ G. Daressy "Textes et dessins magiques", Catalogue général des antiquités égyptiennes du musée du Caire: (Nr. 9401-9449), (Le Caire. Musée égyptien: 1903), 4, pl. 2; H. Gauthier, Dictionnaire des noms géographiques contenus dans les textes hiéroglyphiques, III (1926), 121. 


\section{تمائم تل تبلله وعلاقتها بعبادة أوزيريس}

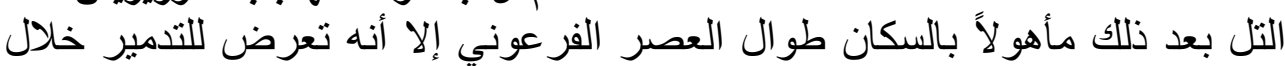
الغزو الفارسى، ثم استعمل كجبانة رئيسية خلال العصرين اليونانى و الرومانى. 4

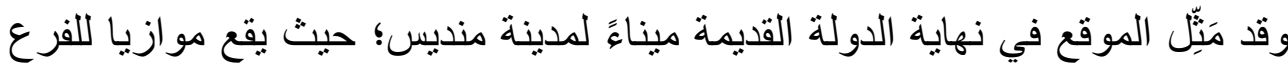

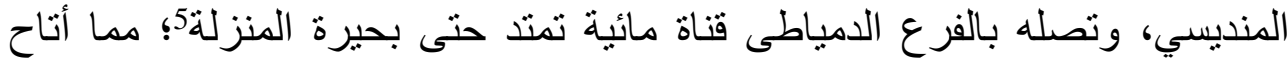

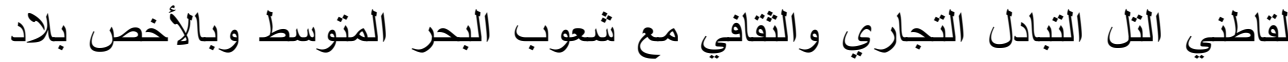
اليونان حيث تثير إلى ذلك القطع الفخارية المكتشفة بالتل. 6 ثنانيا: تاريخ الحفائر بالموقع:

شهد التل عديدا من الحفائر؛ أهمها: حفائر جامعة تورنتو بكندا التي أجريت بين

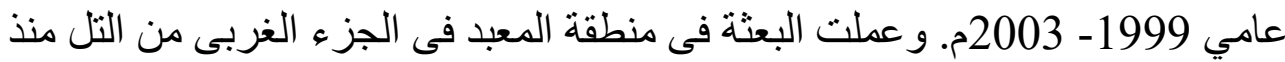
2001م.7 وكان لتفتيش آثار الدقهلية عديد من أعمال الحفائر بالتل أعوام 1989 و 1992 و2003 و 2010، 2014 وكثفت تلأك الحفائر عن مجموعة من المقابر

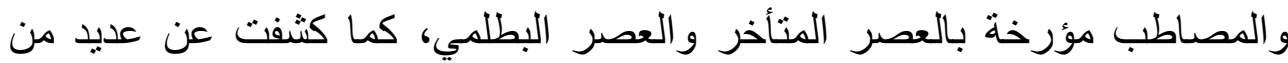
الأو اني الفخارية و التمائم و الجعارين و القطع الأثرية الأخرى. 8

${ }^{4}$ G. Mumford, The First Intermediate Period: Unravelling a 'Dark Age' at Mendes and Tell Tebilla," edited by Susan Redford, The Akhenaten Temple Project Newsletter no.1 (2000), 3-4; Id, "Reconstructing the ancient settlement at Tell Tebilla," edited by Charles Dibble, Bulletin of the American Research Center in Egypt 182 (2002): 18-23; Id, "Tell Tebilla 2001: Investigating a Third Intermediate Period to Ptolemaic temple and cemetery in the Mendesian Nome," edited by Susan Redford, The Akhenaten Temple Project Newsletter (2002), 1-4.

$$
5 \text { يعتقد أن هذه القناة هى البحر الصغير حاليا الذي يبدأ من جديلة، حيث يتصل بفرع دمياط ويمتد }
$$

${ }^{6}$ G. Mumford, "A Late Period riverine and maritime port town and cult center at Tell Tebilla (Ro-nefer)", The Journal of Ancient Egyptian Interconnections, vol. 5 no. 1, (March 2013): 38-67.

7 G. Mumford, "A preliminary Reconstruction of the temple and settlement at Tell Tebilla (East Delta)" in: G. Knoppers \& A. Hirsch (eds.), Egypt, Israel and the Ancient Mediterranean World: Studies in Honour of Donald B. Redford. (Leiden: 2004), 267- 286, Figs.1, 5.

${ }^{8}$ G. Mumford , "Concerning the 2000 Season at Tell Tebilla (Mendesian Nome)", edited by Susan Redford, The Akhenaten Temple Project Newsletter no.1 (March 2001) 1-4; Id, "The 2001 season at Tell Tebilla 


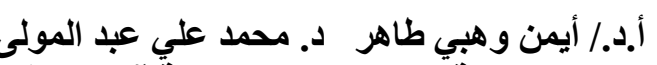

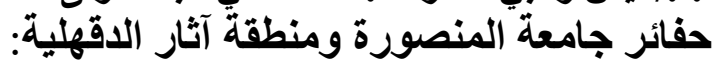

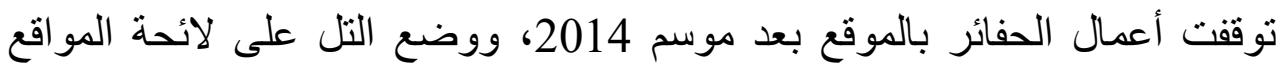
الأثرية ذات الأولوية للحفر. وفي عام 2018 أجريت حفائر مشتركة بين جائ بامعة بعدة

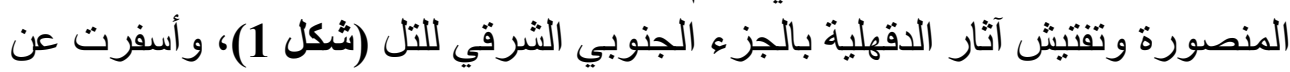

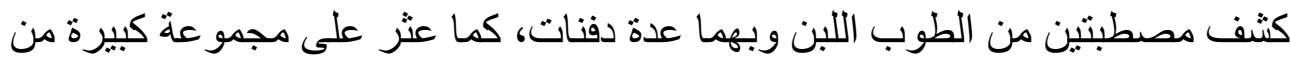

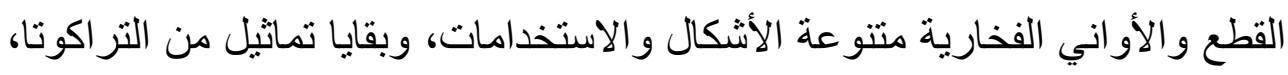

$$
\begin{aligned}
& \text { و عدد كبير من التمائم و اللقى الأثرية. } 9
\end{aligned}
$$

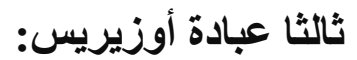

كانت لأساطير عبادة أوزيريس بداياتها في مصر السفلى بمنطقة الدلنا، ويعتقد

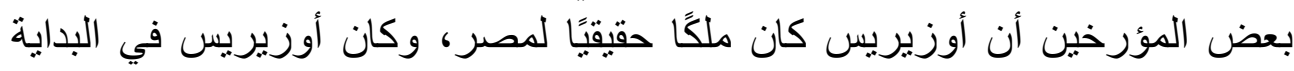

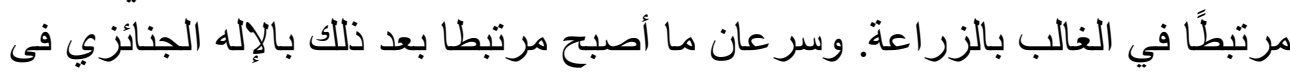

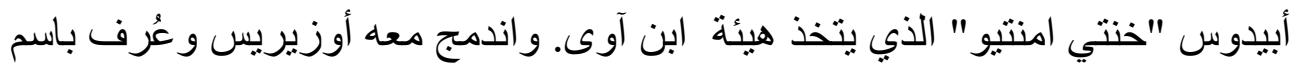

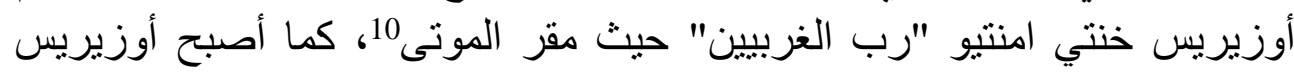

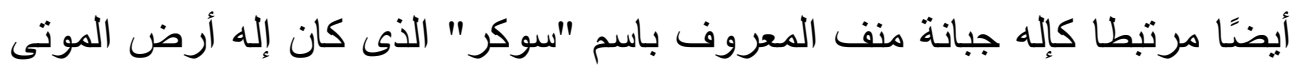

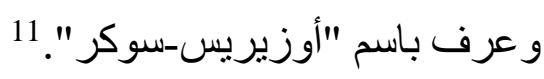

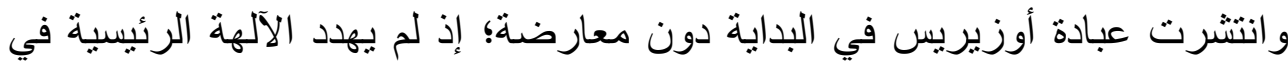

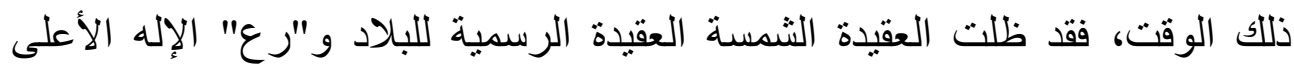

(East Delta)," edited by Patricia Paice in The Society for the Study of Egyptian Antiquities Newsletter, (September 2001), 2, Fig.1 ; Id, "Expedition Reports, Eastern Delta: Tell Tebilla", edited by Charles Dibble, The American Research Center in Egypt: Report and Financial Statements, 2001-2002. Cairo: Publications office of the American Research Center in Egypt, 2002, 13-14.

$$
9 \text { عرضت نتائج الحفائر فى محاضرة بمؤتمر المسح الأثري بالالتا ابريل } 2019 \text { بجامعة المنصورة. }
$$

${ }^{10}$ C. Leitz, Lexikon der ägyptischen Götter und Götterbezeichnungen V, OLA 114 (Paris, 2002), 894.

${ }^{11}$ C. Leitz, Lexikon der ägyptischen Götter und Götterbezeichnungen II, OLA 111 (Paris, 2002), 563-564. 


\section{تمائم تل تبلله و علاقتها بعبادة أوزيريس}

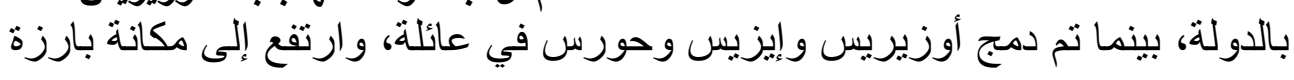
وحمل لقب إله العالم السفلي وملك المئل الموتى. 12

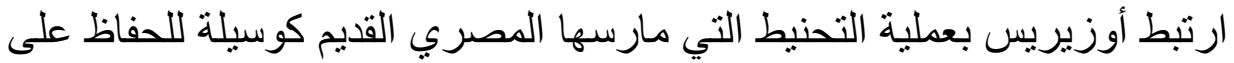

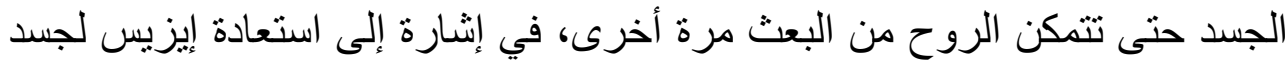

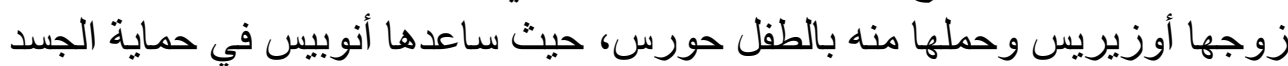
المقس عن طريق حفظه بلفائف الكتان، ولهذا بظهر الكهنة القائمين على تحنيط الكيط

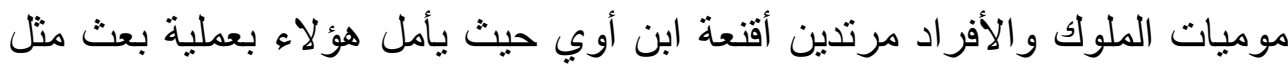
التي حظي بها أوزيريس.

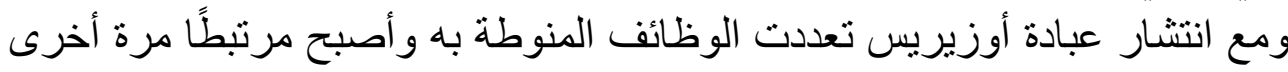

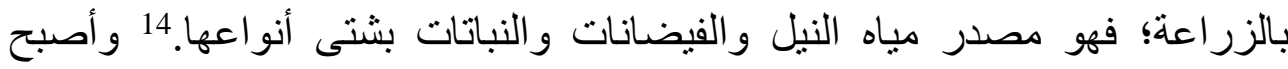

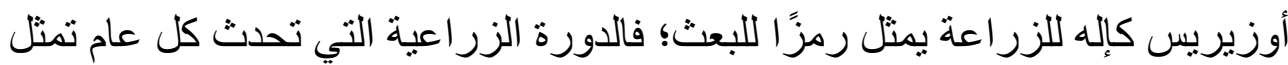

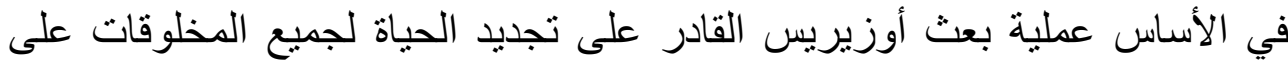

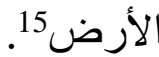

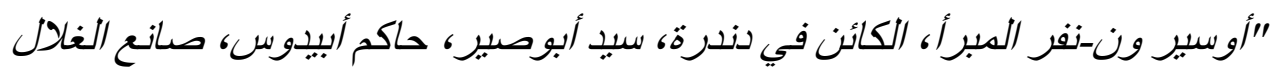

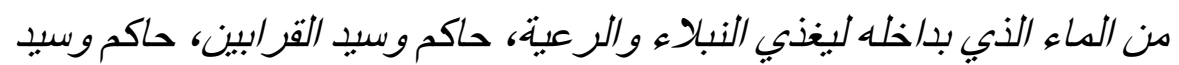

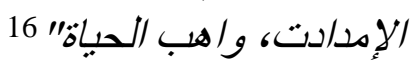

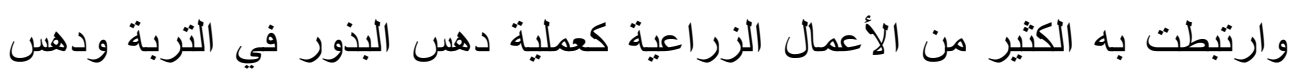

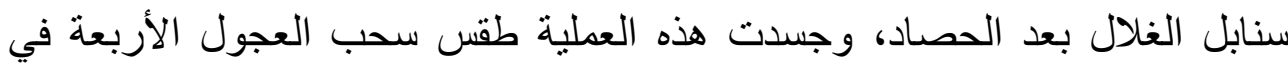

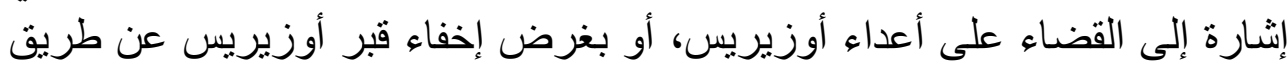

$$
\text { دهس الأرض حول المدخل لمحو معالمه. }
$$

${ }^{12}$ Leitz, Lexikon der ägyptischen Götter, II: 538.

${ }^{13}$ B. Mojsov, Osiris, Death and Afterlife of a God, Oxford (2005), 20.

${ }^{14}$ Mojsov, Osiris, 33, 48.

15 A. Blackman, Osiris as the Maker of corn in a text of the Ptolemaic period, AnOr 17 (Liverpool: 1938), 1-3.

${ }^{16}$ E. Chassinat, Le temple de Dendera, I, (Le Caire 1934), 101, II (15-17).

17 للمزيد عن طقسة سحب العجول الأربعة Hwt bHsw A. M. Blackman and H. W. Fairman, "The significance of the Cermony Hwt bHsw in the temple of Horus at Edfu", JEA 35 (1949), 98-112; Id, "The 


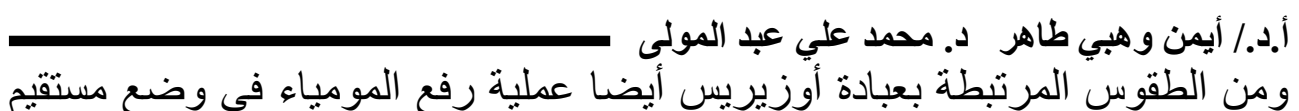
و إجر اء طقسة "فتح الفم". وترمز هذه الطقسة إلى الإنتصار عندما ذهب إنب حورس إلى إلى

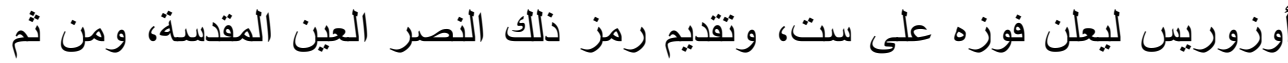
إيقاظه من وعيه، وكان هذا بمثابة الطريق لنهضة وزئة الروح مرة درة أخرى وكذللك إقامة عمود الجد التي ترمز إلى تحقيق العدالة و الاستقرار ــ 18 عبادة أوزيريس فى تل تبلهه:

ترجع شهرة تل تبلله الدينية إلى ارتباطه بعبادة أوزيريس؛ حيث عدة عدّ هذا المكان

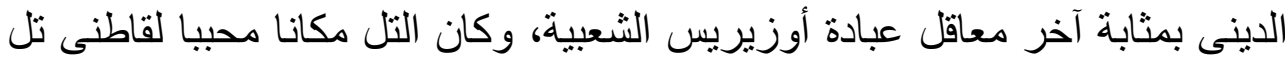

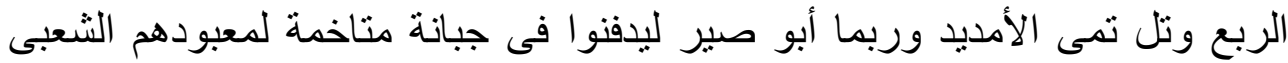

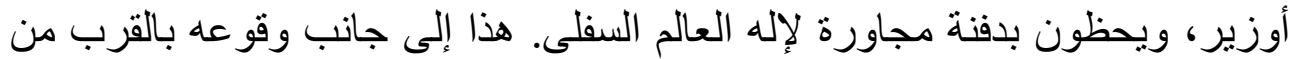

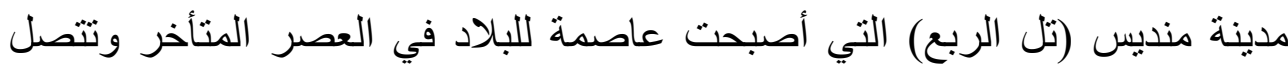

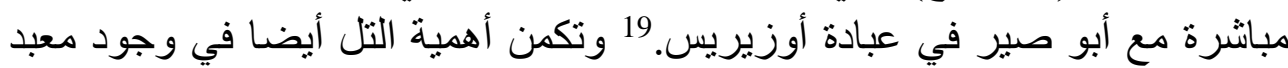

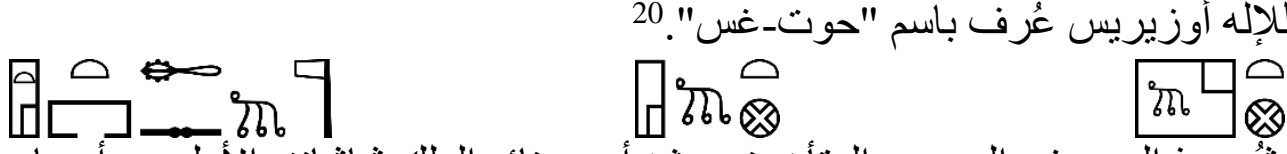
شُشيد هذ المعبد في العصور المتأخرة حيث؛ أمر ببنائه الملك شاشنانق الأول من أحجار

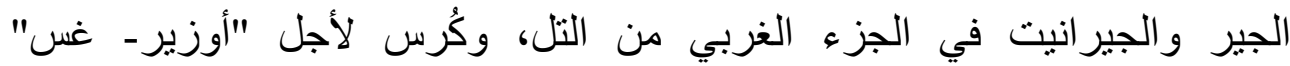

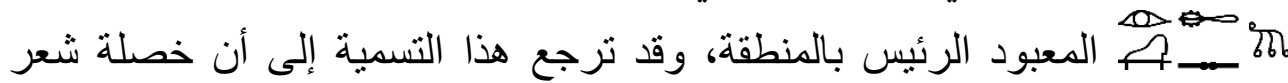

significance of the Cermony Hwt bHsw in the temple of Horus at Edfu", JEA 35 (1950), 63-81; P. Egberts, "Python or Worm? some aspects of the rite of driving the calves", GM 111, (1989); Id, In Quest of Meaning, A study of the Ancient Egyptian Rites of consecrating the Meret-chests and Driving the calves, (Lieden 1995).

${ }^{18}$ Wb. V: 627 (8-10); Edfou I: 165 (16).

${ }^{19}$ C. Edgar, "Notes from my Inspectorate", ASAE 13 (1914), 277.

${ }^{20}$ H. Gauthier, Dictionnaire des noms géographiques, IV (1927), 121-122. 
تمائم تل تبلله و علاقتها بعبادة أوزيريس

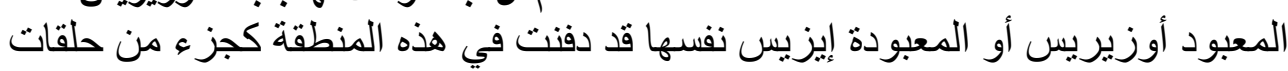

$$
\text { الصر اع بين أوزيريس وست. }
$$

و عرف المعبود أوزيريس في النصوص الموجودة على الآثار التي عُثر عليها بالتل

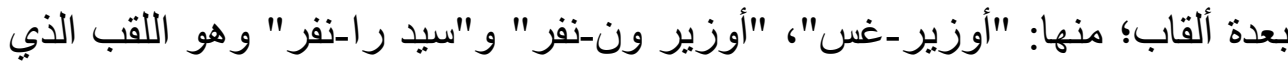

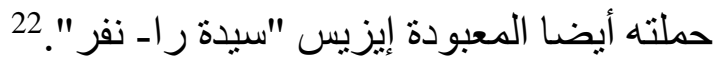

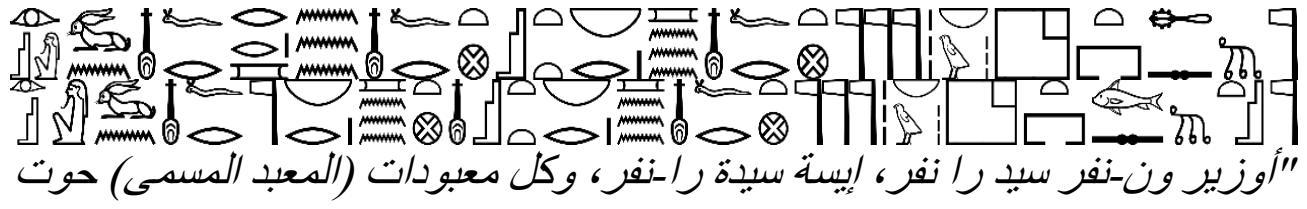

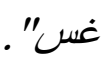

وكما يشير النص فقد عُبد إلى جانب المعبود أوزيريس وزوجته إيزيس فى معبده بنل

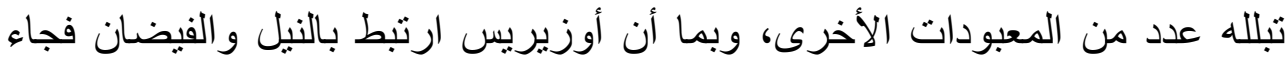

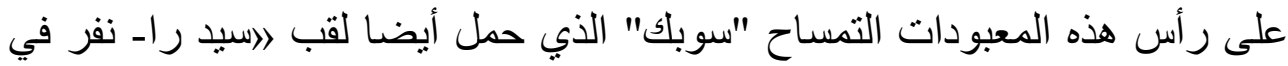

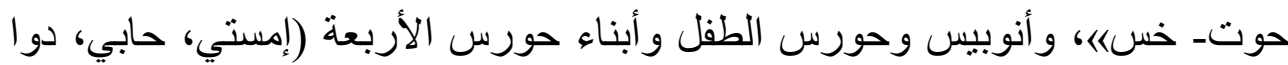
موت إف وقبح سنو إف"23 ليكونوا معا تاسوع ر ا-نفر المقدس،24 ويحتمل أنه كان لكل منهم بالمعبد مقصورة خاصة به تحيط بالمقصورة الكبرى المركزية الخاصة بالئو بالمعبود

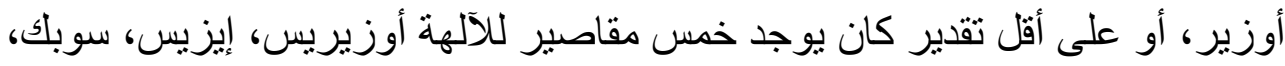

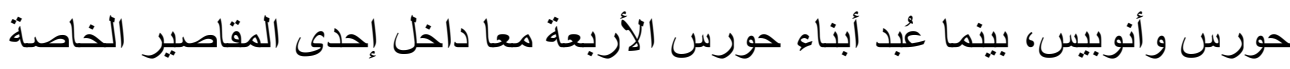

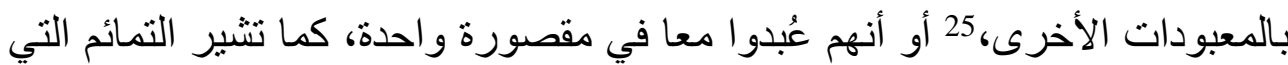

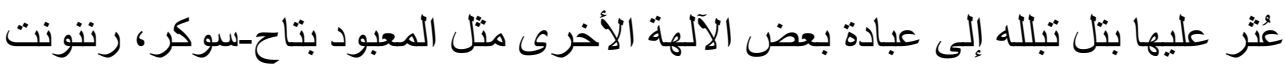

${ }^{21}$ G. Daressy, "Recherches Geographiques", ASAE 30 (1930), 79, 87; Mumford, "the Temple and Settlement at Tell Tebilla", 270; G. Lefebvre, "Textes Egyptiens du Louvre", RdE 1 (1933), 91-92.

${ }^{22}$ M. Chaban, "Monuments recueillis pendant mes Inspections", ASAE 10 (1910), 29.

${ }^{23}$ Daressy, ASAE 30 (1930), 81- 82.

${ }^{24}$ Mumford, "the Temple and Settlement at Tell Tebilla", 274.

${ }^{25}$ Mumford, "the Temple and Settlement at Tell Tebilla, 275, Fig. 5. 


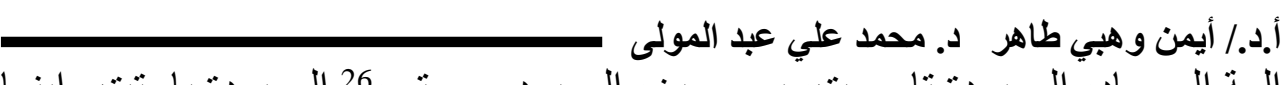
إلهة الحصاد، المعبودة تا-ورت، بس، دئ عين، المعبود جحونى، 26 المعبودة باستت و ابنها ماى-حسي 27. وأسفرت الحفائر التي قامت بها البعثة المشتركة لجامعة المنصورة وتفتيش آثار الدقهلية موسم 2018/ 2019م عن العثور على عدد كبير من التمائم في المناطق

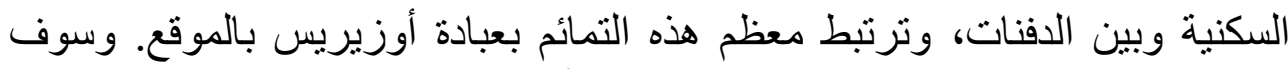

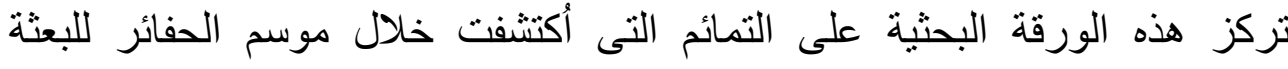

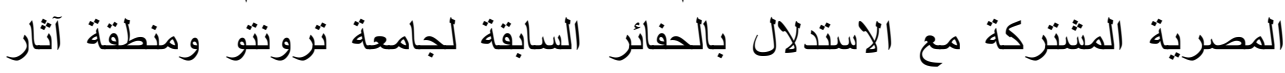

الدقهلية.

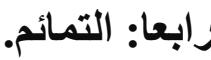

- تمائم المعبود أوزيريس:

من بين الألقاب التى حملها المعبود أوزيريس في تل تبلله لقب "ون-نفر "28 أي

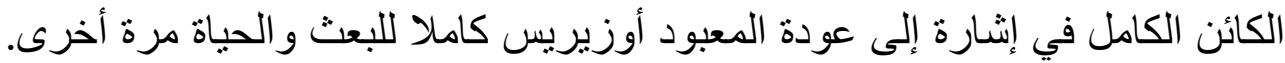

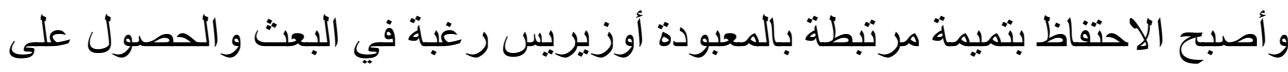

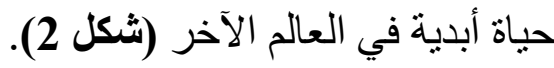
وتوسع الفكر المرتبط بأوزيريس إلى الحياة اليومية في ضمان وفئل وفرة المحاصيل

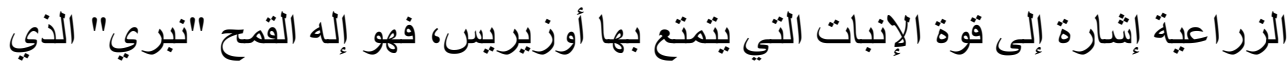

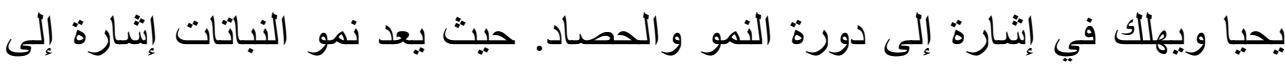
نهوض أوزيريس و عودته مرة أخرى للحياة، وقد عثر بمقبرة توت دوات عنخ آمون بطيبة

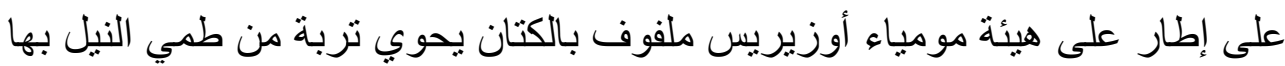

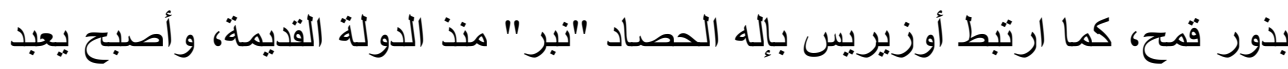

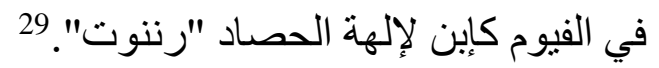

${ }^{26}$ C. Andrews, Amulets of Ancient Egypt, (London 1994), pl. 21 (f).

${ }^{27}$ Andrews, Amulets, 25, pl. 23b.

${ }^{28}$ M. Chaban, ASAE 10 (1910), 29.

${ }^{29} \mathrm{P}$. Wilson A ptolemaic lexikon: a lexicographical study of the texts in the temple of Edfu, OLA 78, (Leuven 1997), 510-511; LGG. IV: 202-203. 


\section{تمائم تل تبلله وعلاقتها بعبادة أوزيريس}

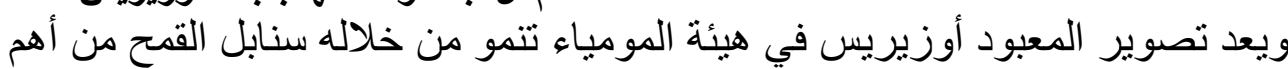

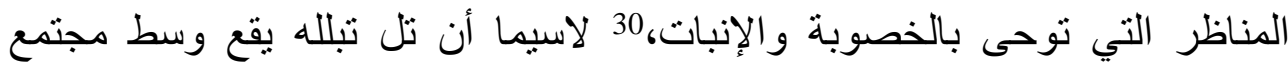

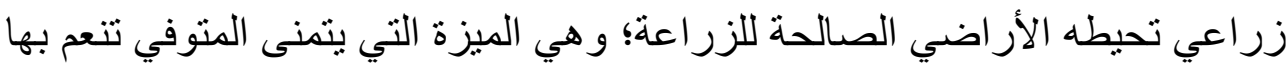
حقوله في العالم الآخر، وقد ورد هذا صر احة ضمن نصوص أحس أحد التوابيت المحفوظة

بمتحف فيتزوليام من عصر الأسرة الحادية والعشرين حيث ذكر هذا النص. 31

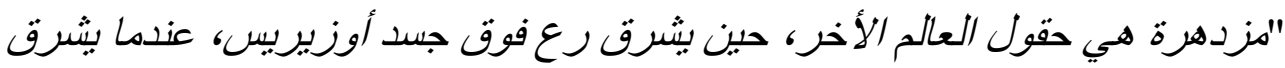
تظهر النباتات ".

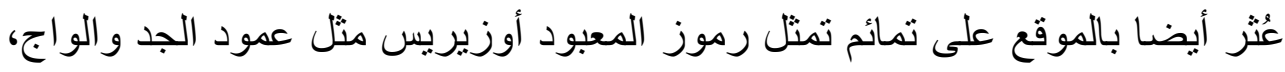

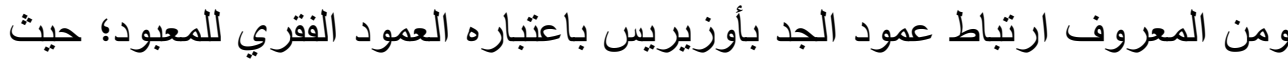
تميزت تو ابيت الدولة الحديثة بتصوير عمود الجد في الأسفل إذ يستقر العمود الفقري

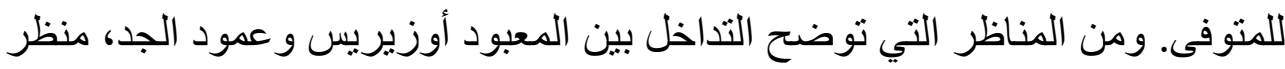

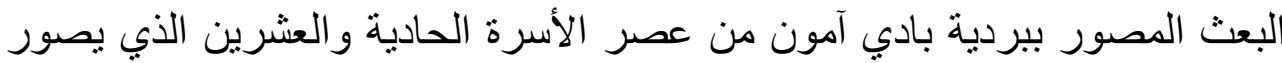

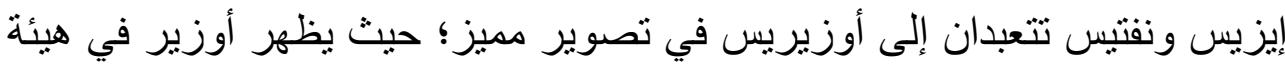

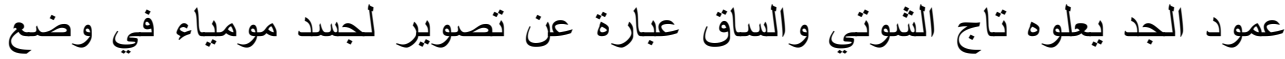

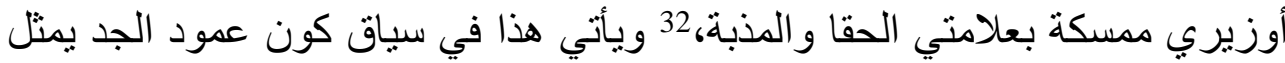
العمود الفقري لأوزير ومقره بوزيريس dw+. وبين ألقاب أوزيريس لقب "أوزير-جدي

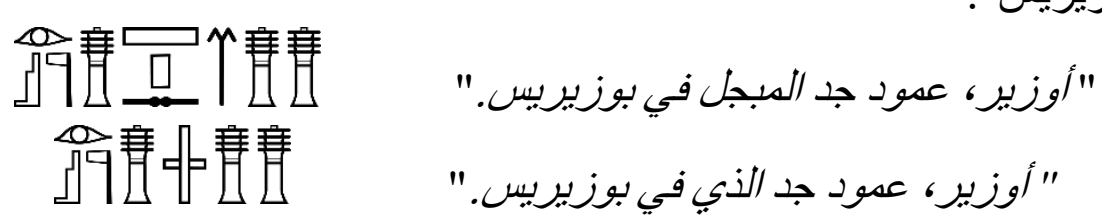

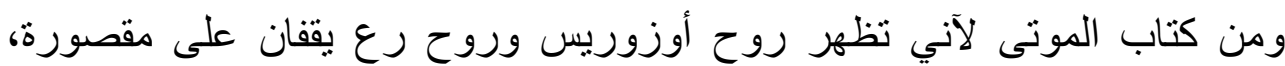

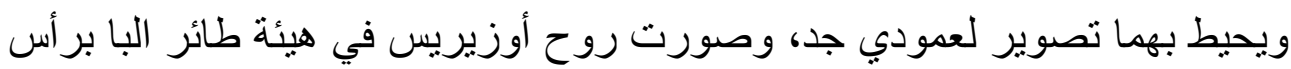

${ }^{30}$ G. Bénédite, Description et histoire de l'île de Philae. lère partie. Textes hiéroglyphiques. Le temple de Philae, I, (Paris 1893), Pl. 40.

31 إريك هورننج، وادي الملوك أفق الأبدية، ترجمة محمد العزب، الطبعة الثانية، (القاهرة: 2002)، 163.

$$
\text { إريك هورننج، وادي الملوك أفق الأبدية، } 166 .
$$

${ }^{33}$ Leitz, Lexikon der ägyptischen, II: 546, 569. 


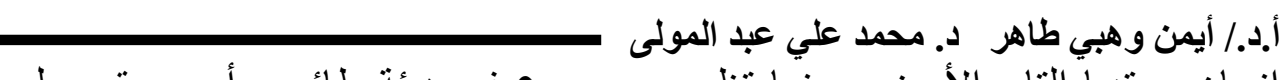

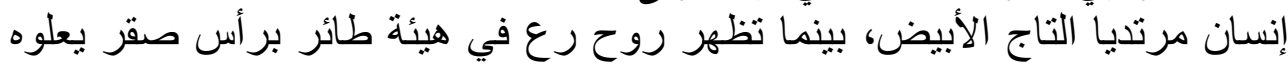
قرص الثمس حيث تلتقيان في منديس.

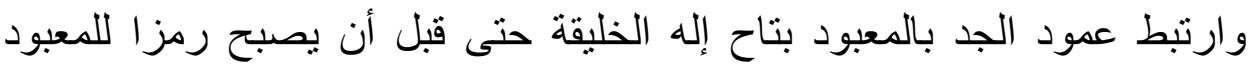

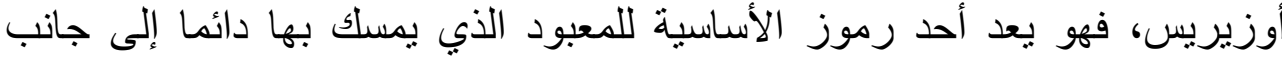

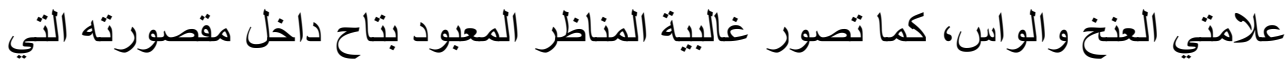
يزينها عمود الجد في أكثر من موضغ لونع.

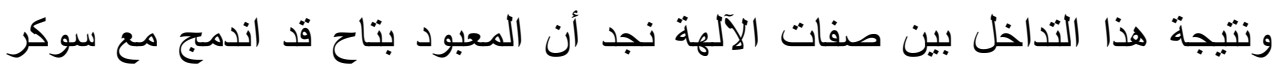

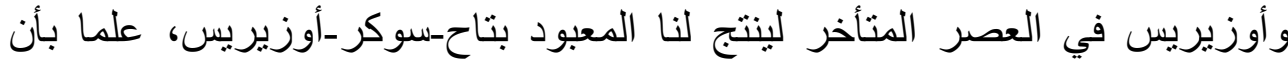
التداخل بين المعبود سوكر وأوزيريس قد بدأت منذ الدولة القديمة؛ فقد عُبد سوكر كإلإله جنائزيا يصور في هيئة المومياء حيث كان مقر عبادته بالقرب جبانة منف، هذا إلى بلى جانب عبادته كإله للخصوبة في هئة والأرضوض.

\section{○89}

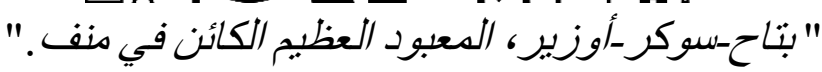

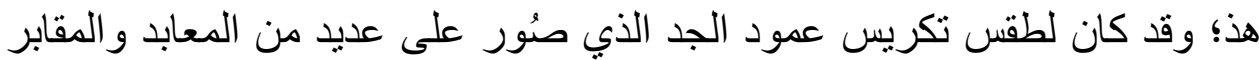

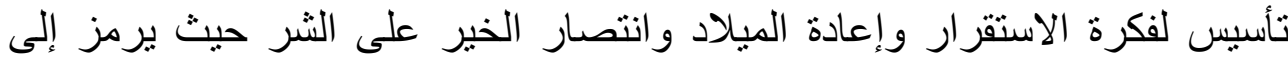
انتصار أوزيريس على ست، 37 فيصور أحد المناظر المصورة بلى بقاعة أوزيريس الداخلية بمعبد سيتى الأول بأبيدوس المعبودة إيزيس تساعد الملك سيتى الأول في

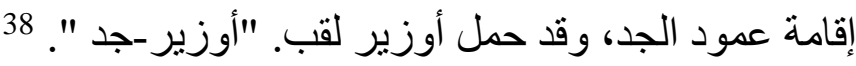

34 والس بدج، برت إم هرو كتاب الموتي الفرعوني، ترجمة: فليب عطية، الطبعة الأولى (القاهرة: 1988)،

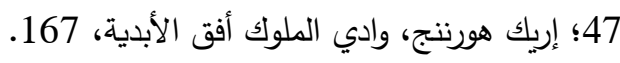

35 A. Calverley, The Temple of King Sethos I at Abydos, Volume IV-The Second Hypostyle Hall, (1958), Pls. 44, 45A, 46, 76, 77.

${ }^{36}$ Leitz, Lexikon der ägyptischen, II: 546, 563-564.

${ }^{37}$ E. Chassinat, Le Mystère d'Osiris au Mois de Choiak, (Le Caire:1968), 756; L. Mikhail, "Raising the Pillar-The Last day of The Osirian Khoiak Festival" , GM 83, (1984), 51-59.

38 A. Calverley, The Temple of King Sethos I at Abydos. Volume III. The Osiris complex, (London 1938), PL. 8. 
تمائم تل تبلله وعلاقتها بعبادة أوزيريس

"أوزير -جد في معبد من-ماعت-رع.

كل هذا جعل عمود الجد تميمة شعبية تجلب الاستقرار وتعطي القدرة على على التجدد لحاملها، لهذا فقد عُثر عليها بأعداد كبيرة في التجمعات السكنية وبين الدفنات البسيطة لعامة الشعب.

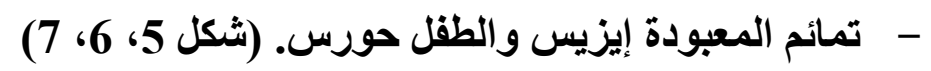

قدست إيزيس في تل تبلله كونها سيدة را-نفر وزوجة المعبود الرئيس بورة بالتل

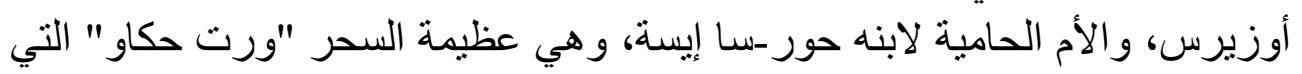

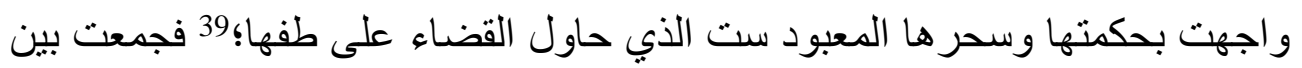
صفات الأمومة والحماية، لهذا كان من الطبيعى العثور على تماثيل وتمائم لها سواء للعبادة أو للتبرك الاكو

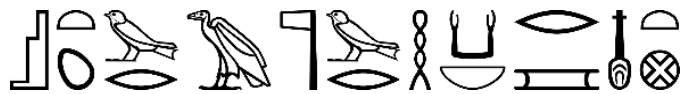

$$
\begin{aligned}
& \text { "إيزبس العظبية، الأم الإلهية، عظبهة السحر، سبإة را-نفرت". } 40
\end{aligned}
$$

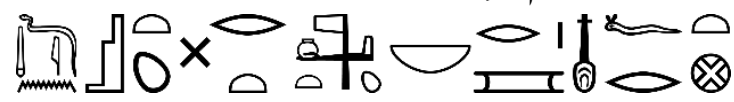

$$
\begin{aligned}
& \text { "تلاوة بواسطة إيزبس العظبية، الأم الإلكية، سبية را-نفرت } 41
\end{aligned}
$$

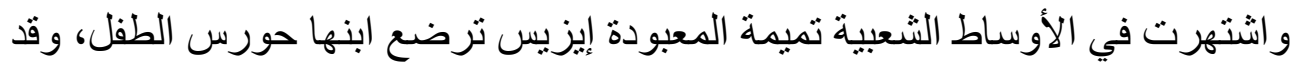

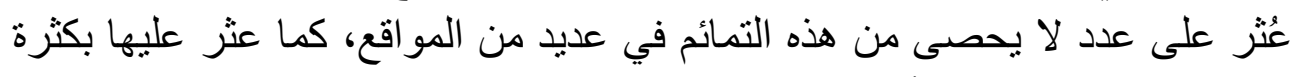

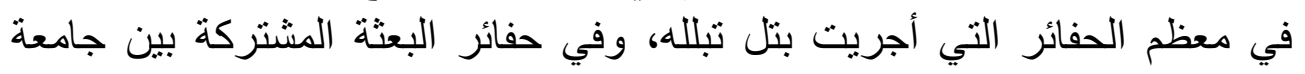

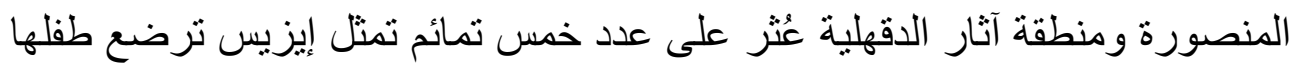

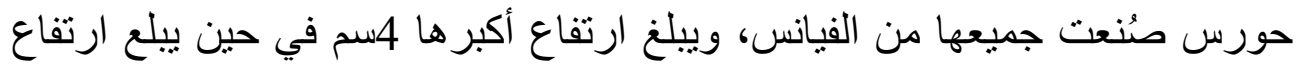
الأصغر 1.7سونم. وتعد هذه التميمة رابطا مهما للأمومة و الطفولة في مصر القديمة ورمزا للحماية

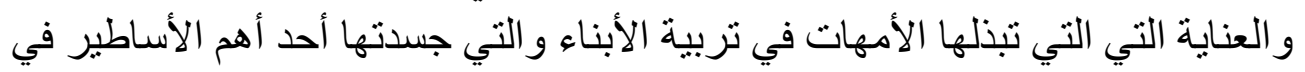

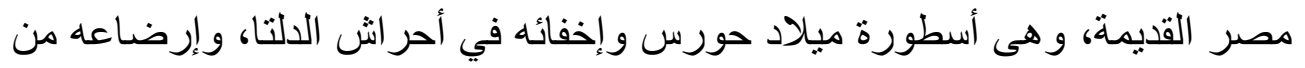

${ }^{39}$ L. Žabkar, Hymns to Isis in her temple at Philae, (Hanover \& London: 1988), 21- 22, Fig. 2

${ }^{40}$ Daressy, "Textes et dessins magiques", 4, pl. 2.

${ }^{41}$ J. Dumichen, Geographische Inschriften altagyptischer Denkmaler, II, (Leipzig: 1866), pl. 42, N. 18. 


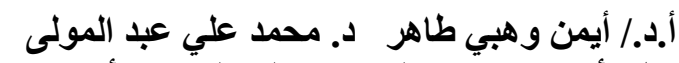

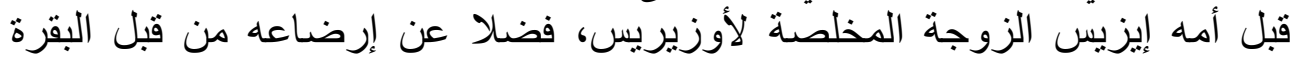
حتحور وعنايتها به. واندمجت المعبودة حتحور مع إيزيس و عُبدت معها بمعبدها لهائها

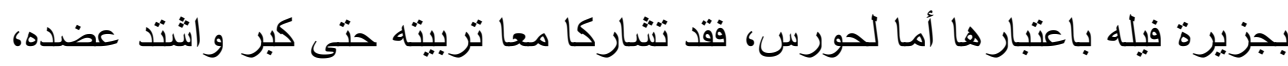

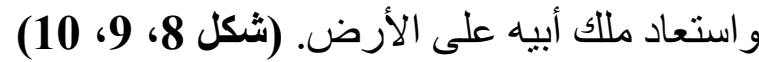

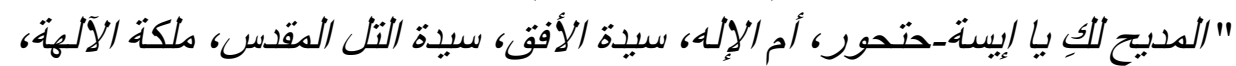
أنت أم الإله حورس.

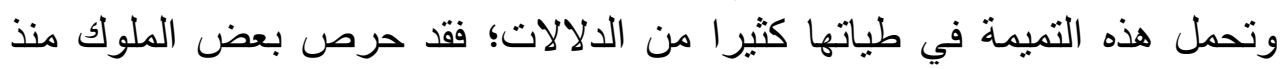

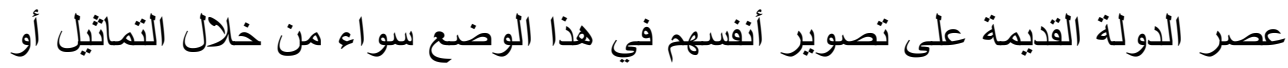
في صور على جدران المعابد الكبرى، فصور الملك أوناس بمعبده الجنائزي بسقارة يرضع من إحدى الربات، كما عُشر للملك بيبي الثاني من الأسرة السادسة على على تمثنال يصوره جالسا تحمله أمه على ساقيه. وفي عصر الأسرة الثامنة عثر عثر بالدير البحري على على مقصورة للملك تحتمس

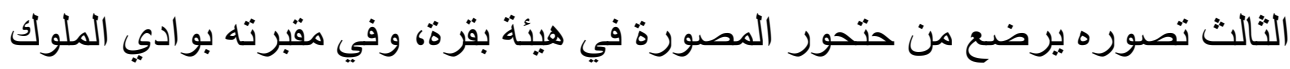
نV.34

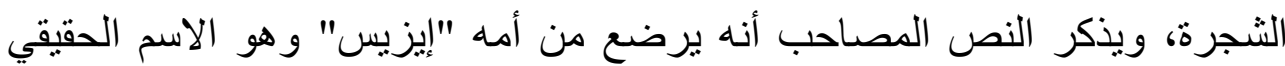
لأمه الزوجة الثانية للملك تحتمس الثاني. 43

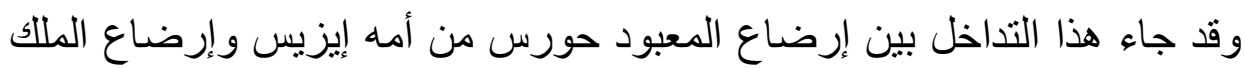

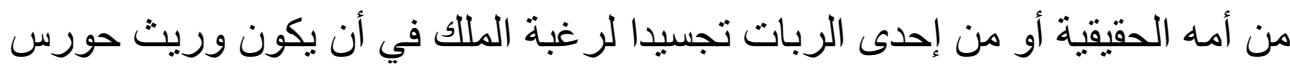

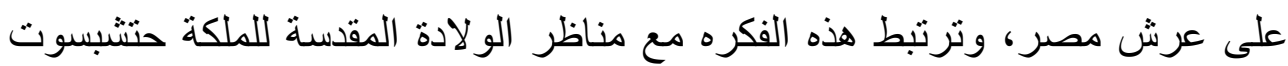

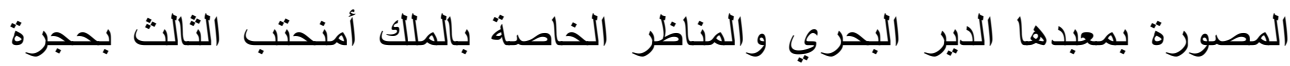

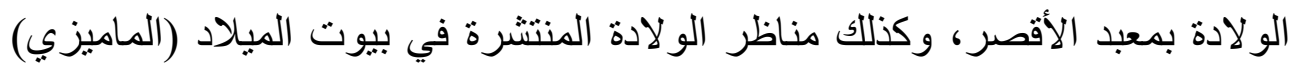

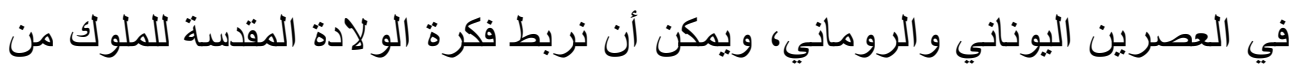

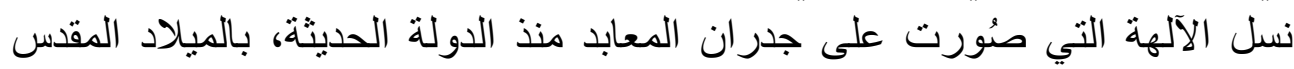

${ }^{42}$ Žabkar, Hymns to Isis, Fig. 2 43 إريك هورنتج، وادي الملوك، 38- 39، 279، لوحة 72. 


\section{تمائم تل تبلله وعلاقتها بعبادة أوزيريس}

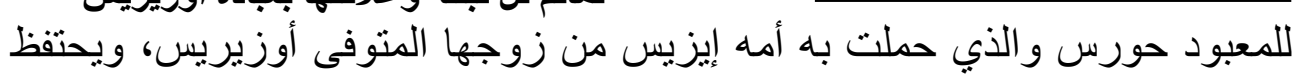
معبد أبيدوس بمنظر لهذه العملية المقدسة، وقد اتخذت فيه إيزيس شكل طائر الحدأة. 44

\section{تمائم علي هيئة التمساح:}

من المميز بموقع بتل تبلله العثور على التميمة الأكبر التي تمثل إيزيس ترضع

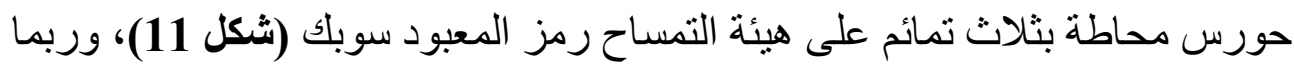
كان لوجودها معا بهذا الثكل رمزية معينة باعتبار أن للتمساح دوردية دورا في أسطورة

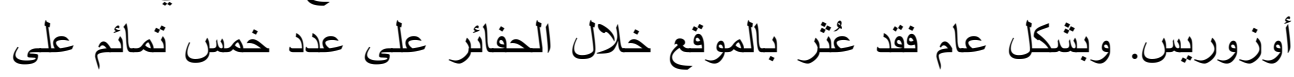

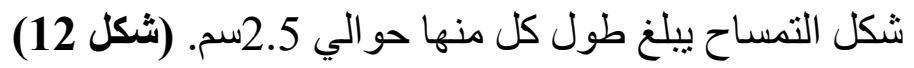

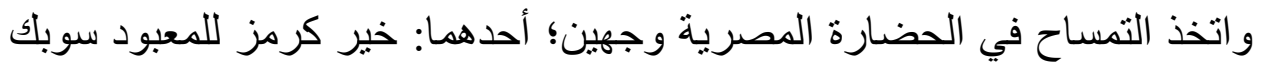
الذي عبد في عديد من المناطق أهمها مركز عبادته في الفيوم التي عرفت فئ باسم

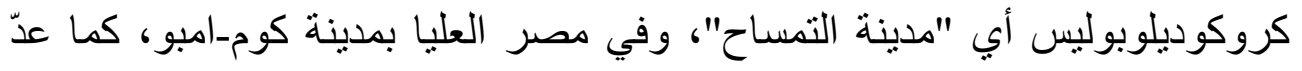

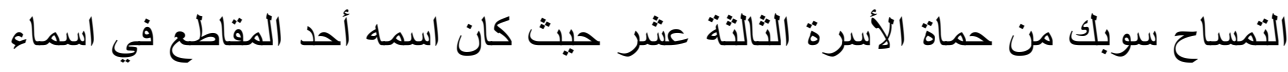
عدد كبير من ملوكها وصل لتسعة ملوك، كما ورد سوبك في اسم آخر ملوك الأسرة

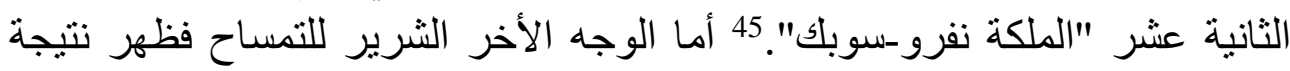

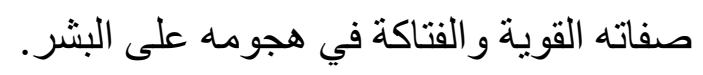

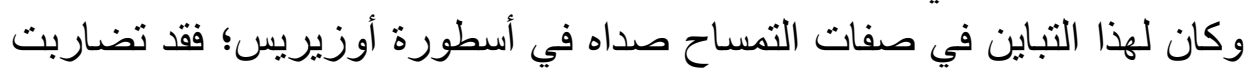

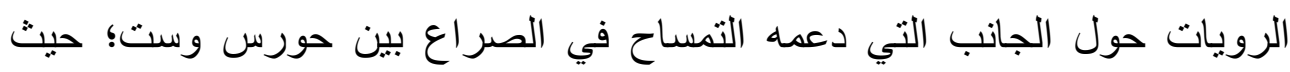

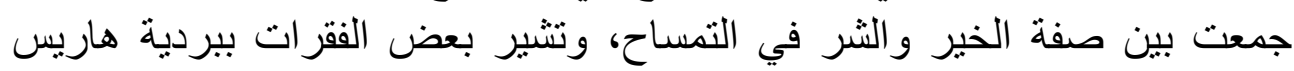

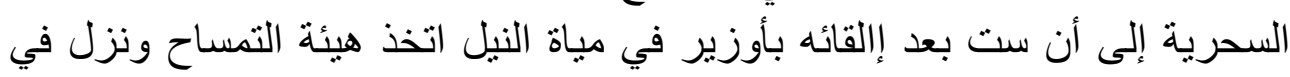
النهر للبحث عن جسده. 46

${ }^{44}$ D. O'Connor, Abydos Egypt's First Pharaohs \& the Cult of Osiris, (London: 2009), 36, Fig. 9.

${ }^{45}$ J. Beckerath, Handbuch der ägyptischen Königsnamen, MÄS 49 (Mainz 1999), 86- 105.

${ }^{46}$ H Lange, Der Magischer Papyrus Harris, (Kopenhagen: 1925), VIII, 9-10, 11, 12; W. Dawson, "Anastasi, Sallier, and Harris and thier Papyri", JEA 35 (1949), 163; R. H. Wilkinson, Symbol \& Magic in Egyptian Art, (London: 1994), 94. 
أ.د./ أيمن وهبي طاهر د. محمد علي عبد المولى إلى معبد كما نجد أن النصوص أنص في معبد إدفو على على سبيل المثنال تشير إلى أن أنصسار المعبود

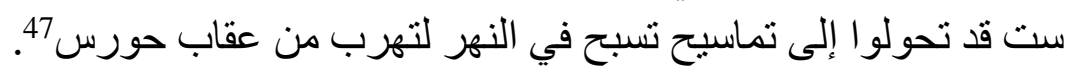
هذا؛ وتصور أحد المناظر المصورة على الجدار الداخلي للسور المحيط بمعبد إدفو

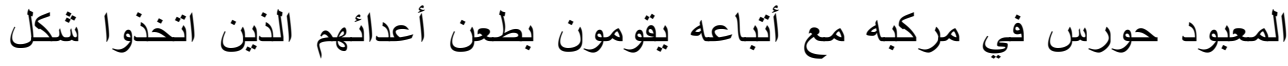

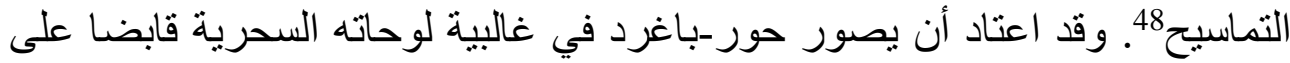

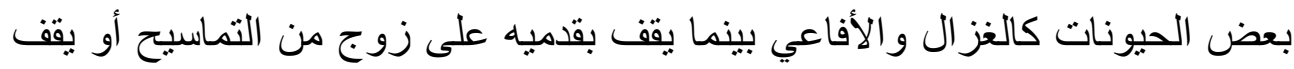

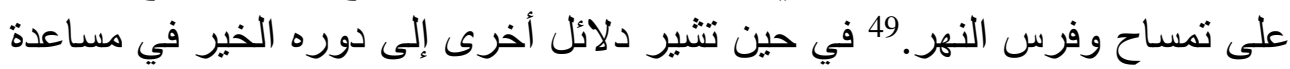
حورس ضد ست ولهذا نجده يقد في معبد كوم-امبو إلى جوار المعبود حورس الكبير "حور-ور". كما يصور أحد المناظر بمعبد فيله التمساح يحمل على فئل ظهره

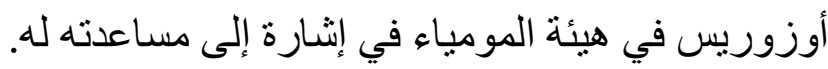

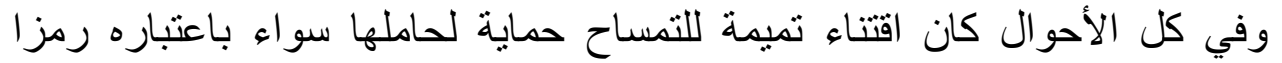

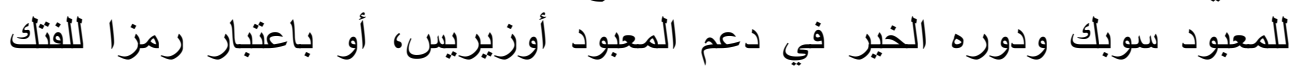

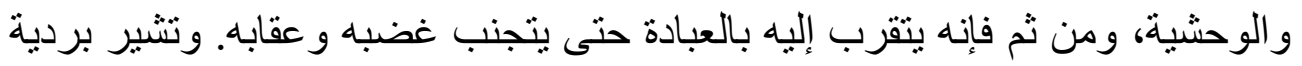

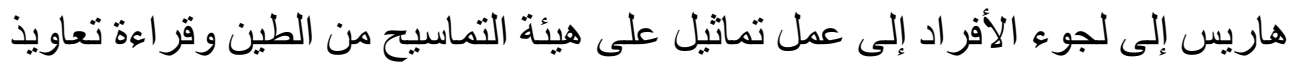

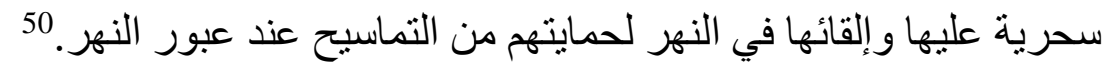
تمائم علي هيئة جحوتي: (شكل 13، 14، 15، 15، 16 16)

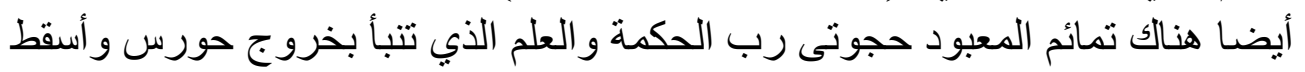
أعداءه بكلامه، 51 كما تشير بردية هاريس إلى أن أوزير قد اتخذ هيئة القرد ـأحد

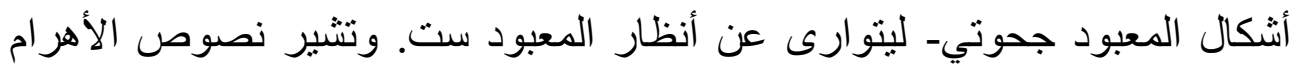

47 محسن لطفي السيد، أساطير معبد إدفو شرح وترجمة للمتون والطقوس من الدصرية القديمة إلى العربية، القاهرة 2003، 268.

$$
48 \text { محسن لطفي السيد، أساطير معبد إدفو، 288- } 2003 \text { مرن } 289 .
$$

${ }^{49}$ Daressy, "Textes et dessins magiques", pls. 1:8.

${ }^{50}$ F. Griffith, Herodotus II. 90. Apotheosis by Drowning, ZÄS 46 (1909), 132134 ;

آمال صمويل، صدى أسطورة أوزير فى بعض المعتقدات الدينية والجنائزية ومراكز عبادته فى ضوء

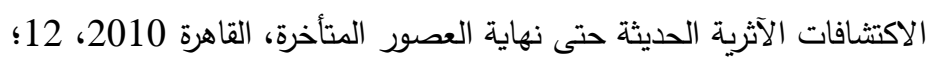
51 محسن لطفي السيد، أساطير معبد إدفو، 304. 


\section{تمائم تل تبلله وعلاقتها بعبادة أوزيريس}

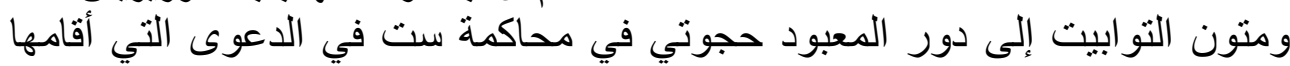

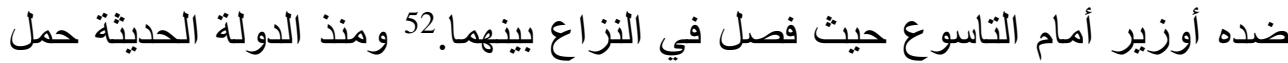
جحوني لقب "wp- rHwy" "الذي يفصل بين المتنار عين" في إثارة إلى دوره في وندي

الفصل بين حورس وست. وتثير نصوص التوابيت والفصل السابع من كتاب الموتى إلى دور المعبود جحوتي في علاج عين حورس التي تضررت أثناء صر اعه مع ست، بعد أن فصل بـت بينها

$$
\text { وأوجد السلام تصن. }
$$

\section{تمائم علي هيئة تاورت وبس: (شكل 17، 18، 19، 19)}

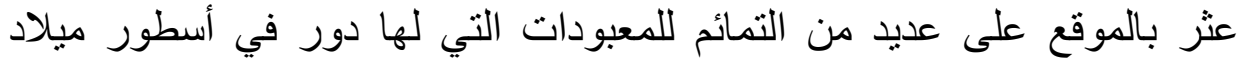

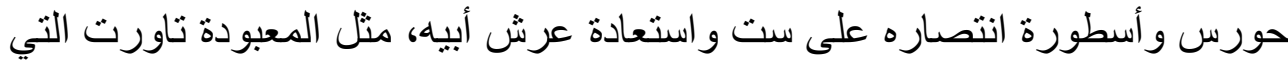

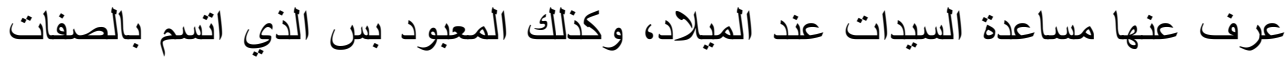

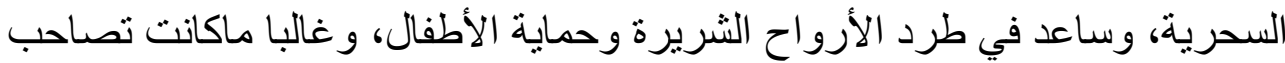

$$
\text { صورته المعبود حورس الطفل على لوحات حورس السحرية. } 55
$$

تميمة عين الودجات: (شكل 20، 21)

تعد تميمة عين الودجات من أثهر التمائم التى عثر عليها بالمواقع الآثرية المصرية، وكثفت حفائر البعثة المشتركة بثل تبلله عن عدد كبير من تمائم "عين

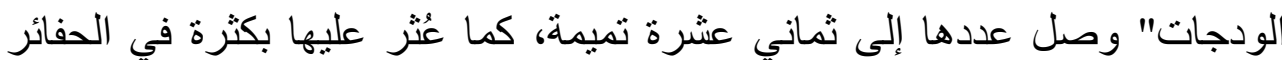

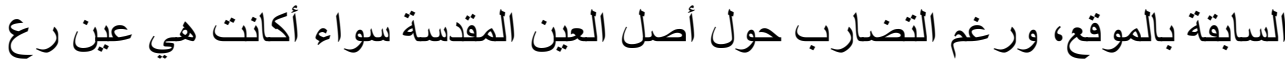
اليمني أم عين حورس المتضررة من الصر اع بينه و عمه المعبود ست، 56 ويلاحظ أن أن كتابة اسم أوزيريس بالخط الهيرو غليفي يكون دائما بعلامة العين مستقر فوق قرصن

${ }^{52}$ Pyr. 956; Pyr. 1963 (a-b); Faulkner, Spell 7, 1, 19-20, 3;

$$
\text { آمال صمويل، صدى أسطورة أوزير، 2010، 19، } 51 \text {. }
$$

${ }^{53}$ P. Boylan, Thoth, The Hermes of Egypt, (Oxford: 1922), 44-45; Wb. I (1971) 299,1-2; Edfou I: 297 (15), II: 73(14), III: 250 (7, 12), 251 (4), IV: 50 (12), 52 (4); Wilson, A ptolemaic lexikon, 221.

${ }^{54}$ A. de Buck, The Egyptian Coffin Texts 4, Texts of Spells, Chicago (1951), 66 (j); R. Faulkner, The Ancient Egyptian book of the dead, (London: 1985), Chapter 17, Pl. 8; Faulkner, The Ancient Egyptian Coffin texts, I, Spell 335.

${ }^{55}$ Daressy, "Textes et dessins magiques", pls. 1:8.

$$
56 \text { والس بدج، كتاب الموتي الفرعوني، } 46 .
$$




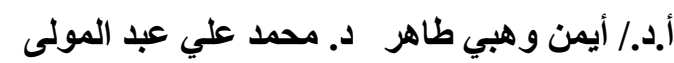

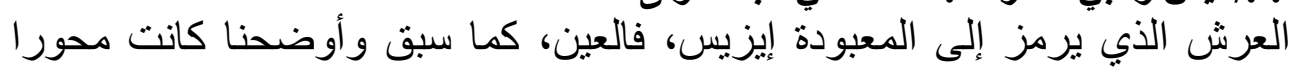
مهما في الصر اع الذي نشب بردي الـين أوزوريس وست.

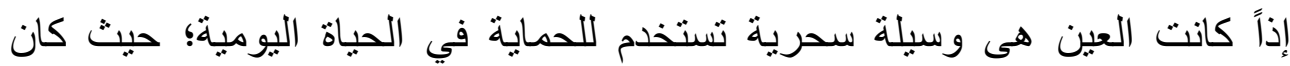

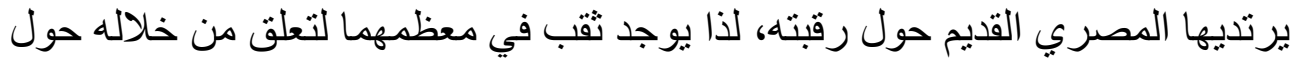

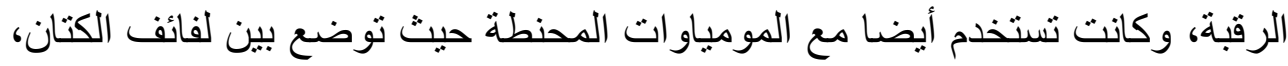

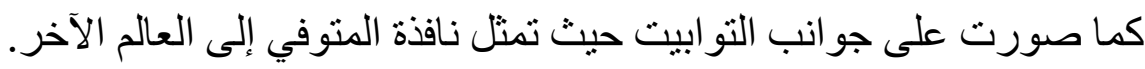

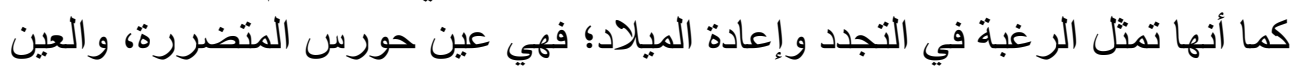

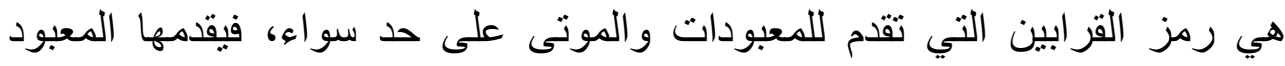

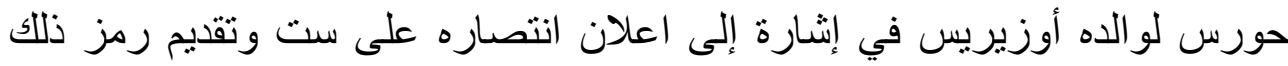

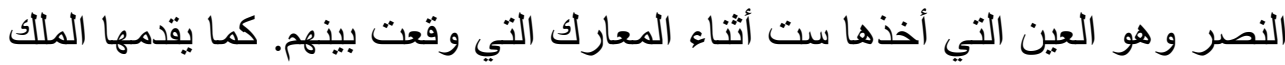
أمام عرش أوزيريس باعتباره حورس التها على الأرض.

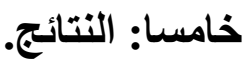

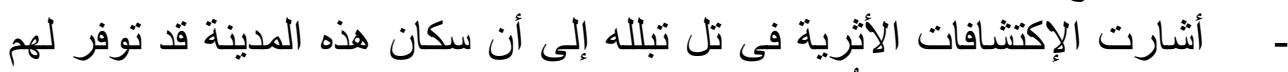

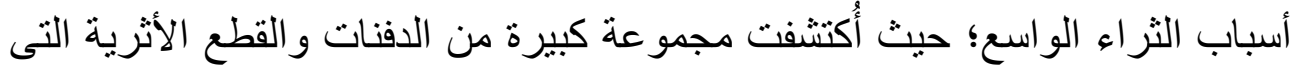

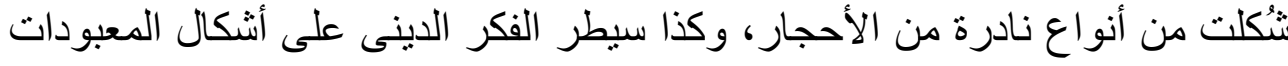

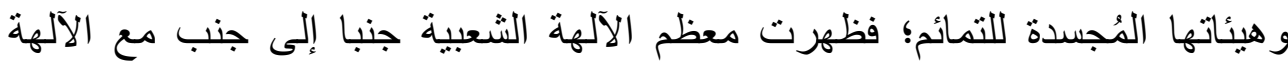

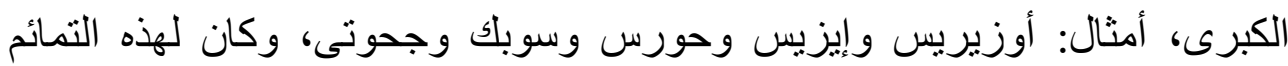

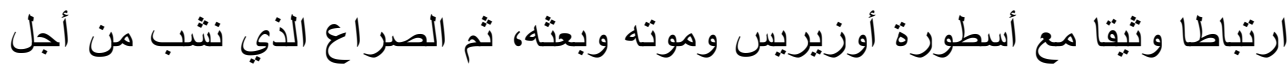

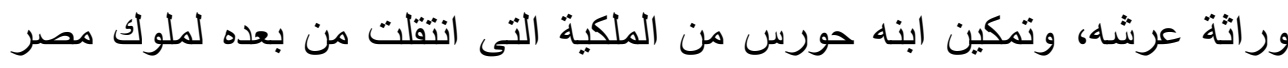
تباعاً.

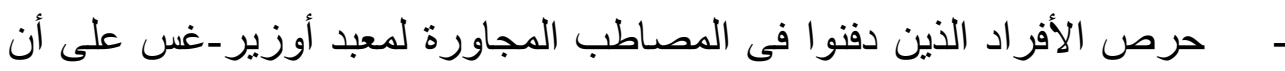

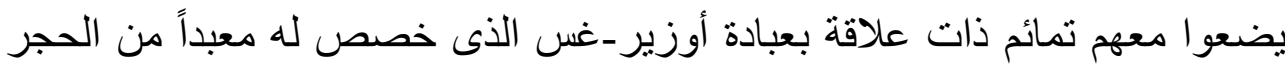

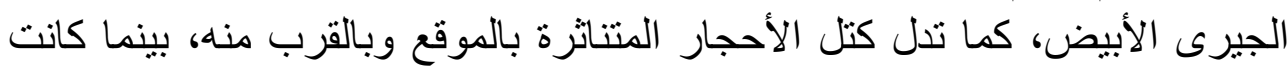
واجهة المعبد مشيدة من حجر الجرانيف تليت الول الوردى.

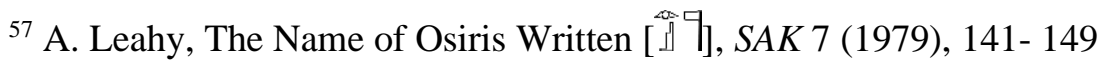

${ }^{58}$ B. Mojsov, "Osiris", 33;

إريك هورنتج، وادي الملوك أفق الأبدية، 214. 


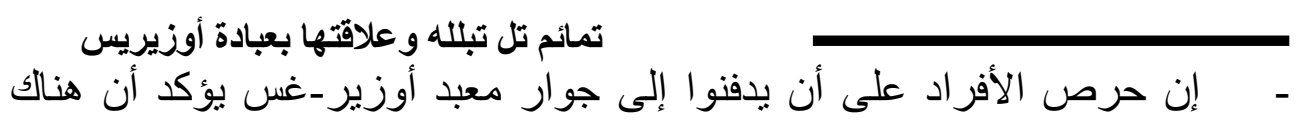

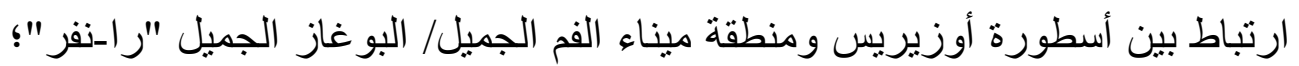
فهل خرجت جثة أوزيريس من هذا المكان وانتقلت للبحر المتوسط فئ رحلتها إلى بلى ببلوس؟ وهل استقرت خصلة إيزيس التى قطعتها تعبيرا عن حزنها على زوجها

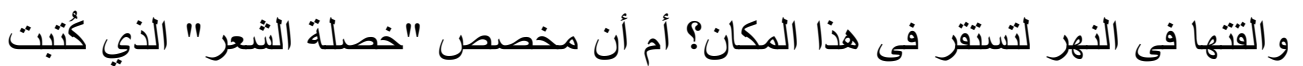
به كلمة "غس" يثير إلى جزء من جسد أوزيريس حيث كانت كل منطقة تز عم أن بها

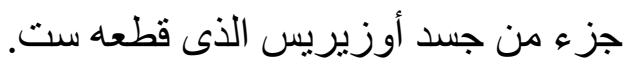

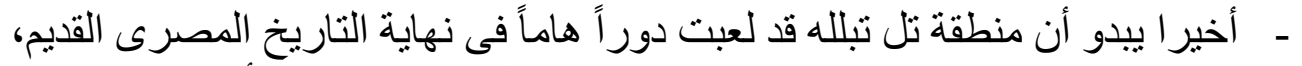

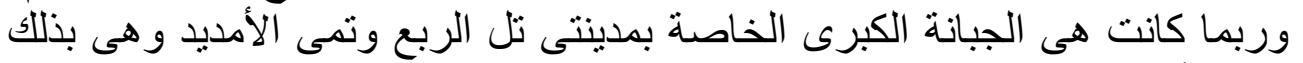
تمثل "أبيدوس الدلتا". سادسا: الأشكال والصور: الصال:

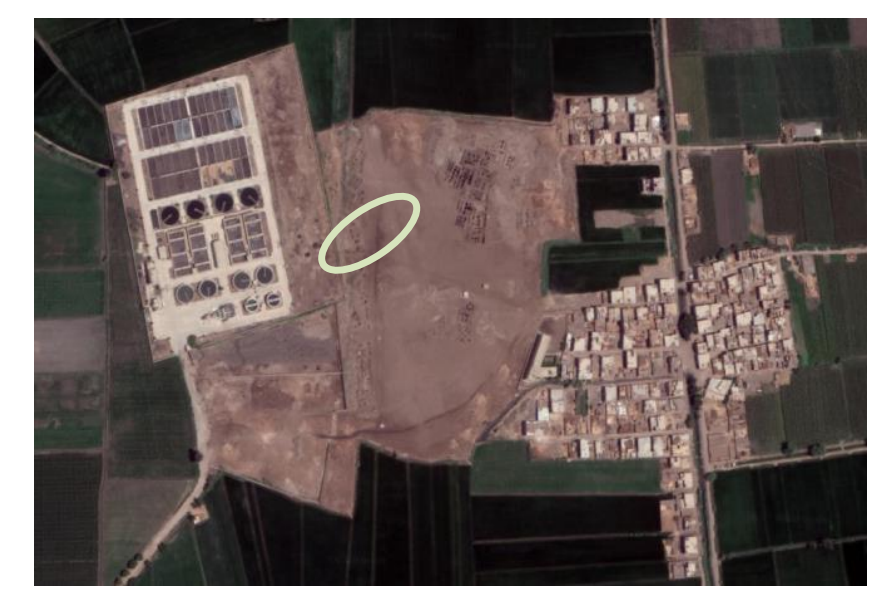

(1)موقع حفائر البعثة المشتركة بالجزء الجنوبي الشرقي للتل. 

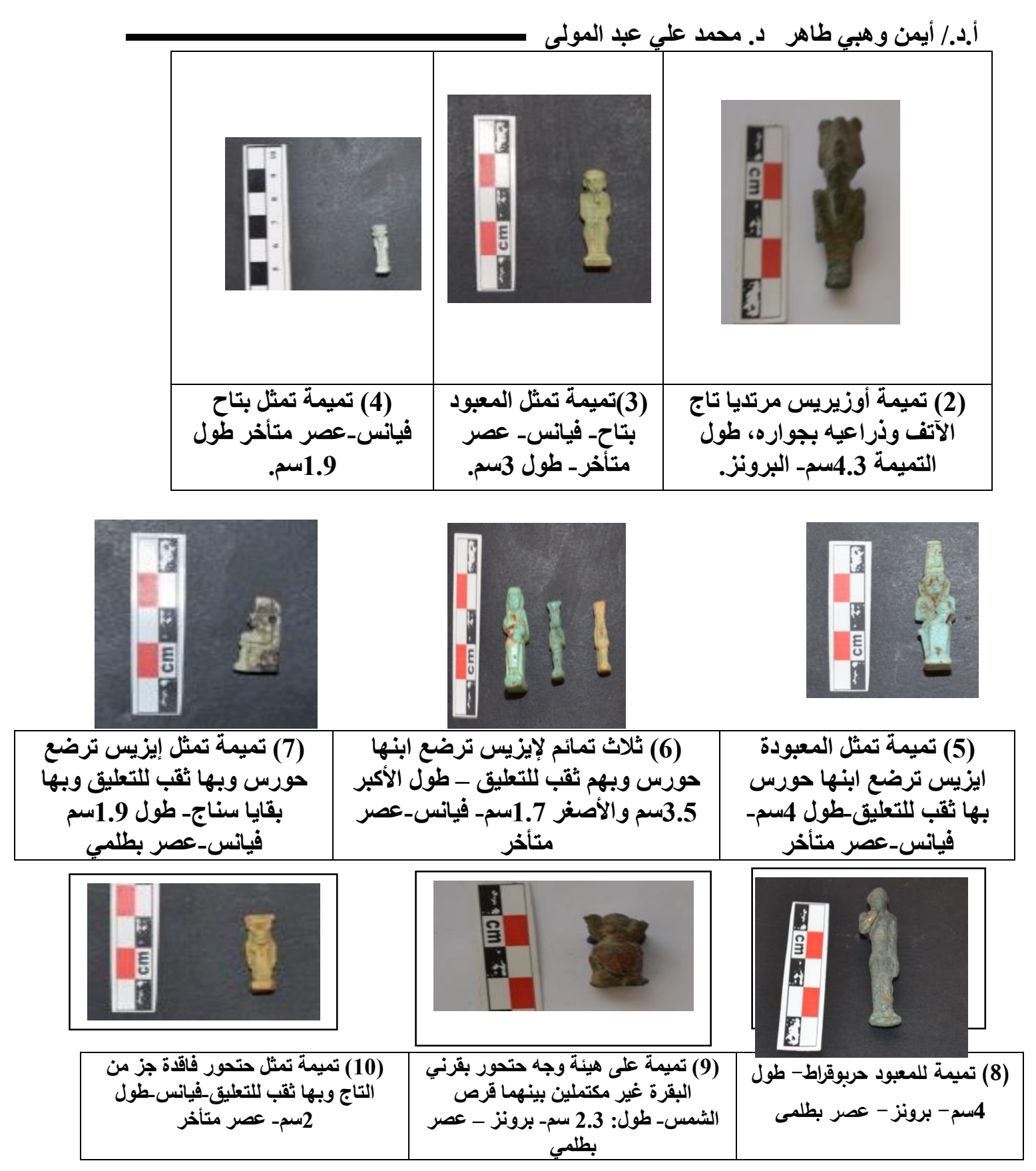
تمائم تل تبلله و علاقتها بعبادة أوزيريس
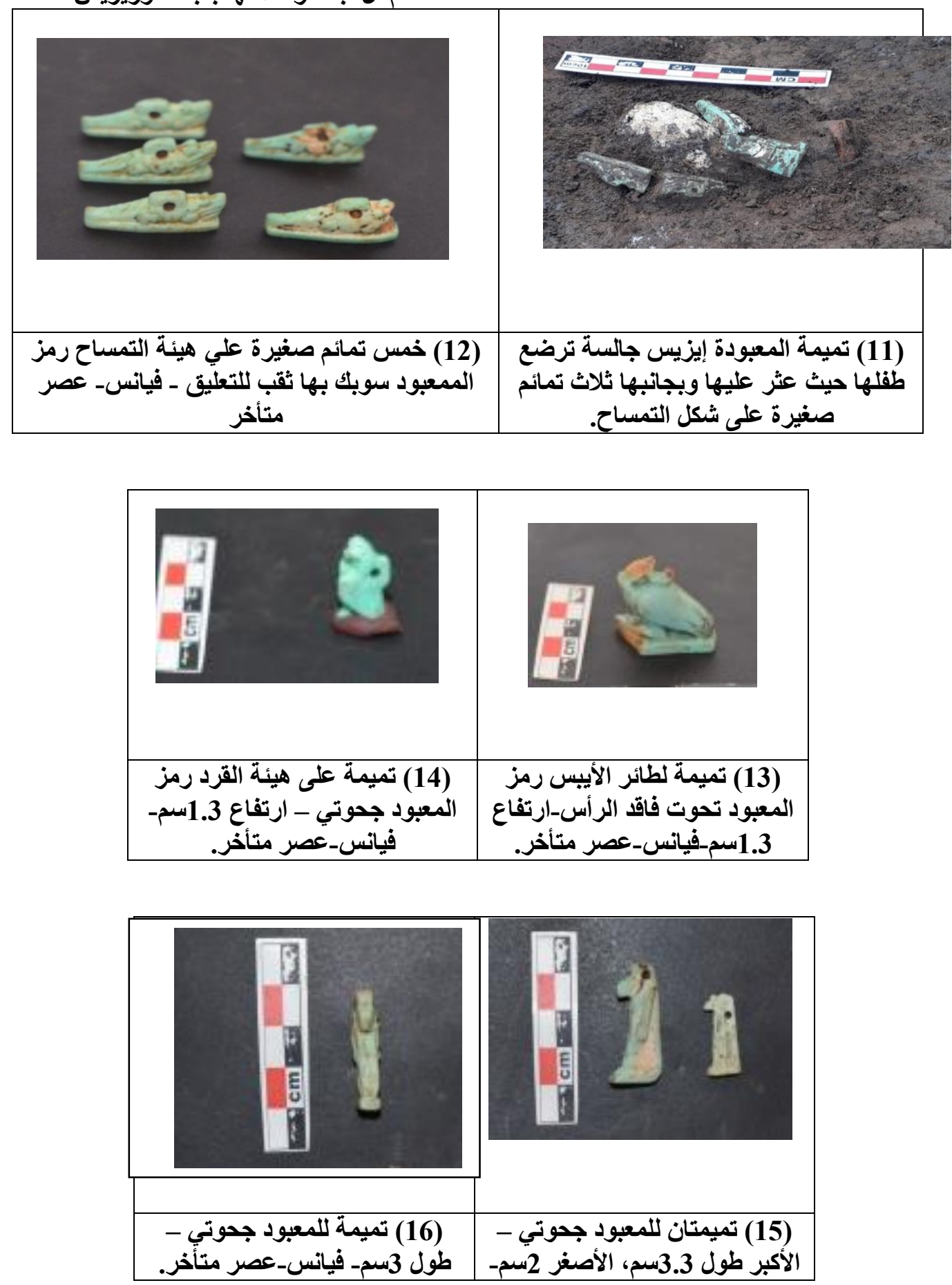

مجلة بحوث كلية الآداب 
أ.د./ أيمن وهبي طاهر د. دحمد علي عبد المولى
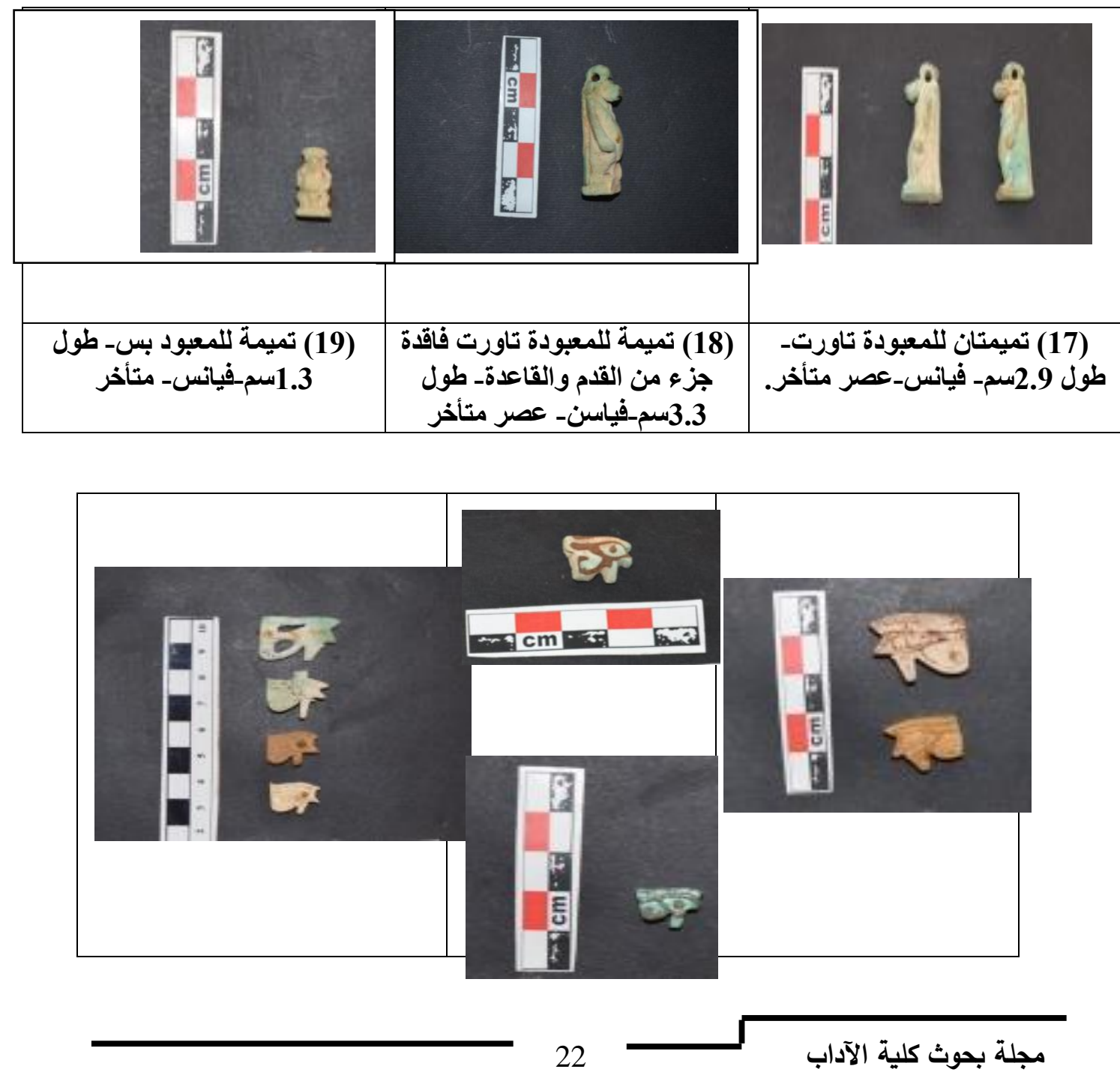
تمائم تل تبلله و علاقتها بعبادة أوزيريس

(20) عدد كبير من تمائم عين الوجات عثر عليها ملقاى بموقع الحفائر ومع الدفنات- طول

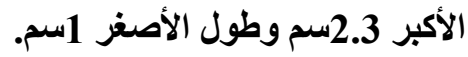

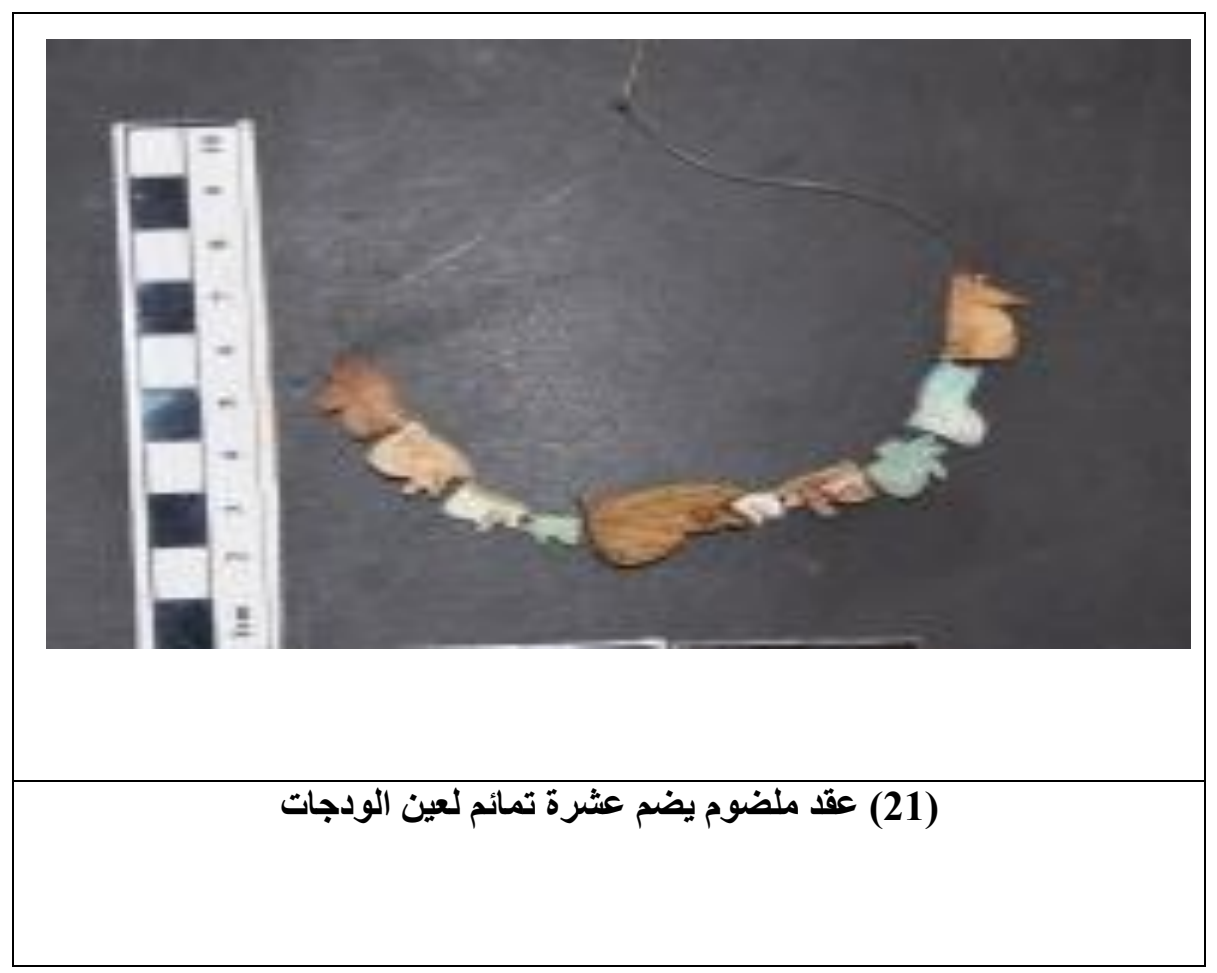

